\title{
Handling concerns raised about doctors: time for local changes
}

Andrew Graeme Rowland, The School of Health and Society, The University of Salford, Salford, UK; North Manchester General Hospital, The Pennine Acute Hospitals NHS Trust, Manchester, UK

Keerthi Mohan, Thames Valley Health Protection Team, Public Health England South East, Public Health England, Didcot, UK

Correspondence to: Andrew Graeme Rowland (andrew.rowland@pat.nhs.uk)

Received: 23 August 2019; Accepted: 4 February 2020

\begin{abstract}
NHS organisations must be assured that appropriate protections and support are in place for their employees, especially when incidents occur or concerns arise. These assurances are an essential part of fostering a just and inclusive culture under an overarching banner of compassionate leadership, while also ensuring that any concerns are properly investigated. In mid-2019, the General Medical Council published their Hamilton review into Gross Negligence Manslaughter. As a result, NHS Improvement wrote to NHS trusts about managing local investigation processes for disciplinary investigations of all types. Employers and educators of healthcare professionals have a responsibility to consider how they will put these recommendations and requirements into practice, yet there is currently no clear implementation guidance. The authors make implementation recommendations which should be considered by NHS organisations and Health Education England as part of their compassionate leadership and just culture processes.
\end{abstract}

\section{Key words}

Disciplinary, Governance, Investigation, Law, Policy, Workforce 


\section{INTRODUCTION}

Healthcare employers must be assured that their employees are appropriately protected and supported during their day to day work, especially when incidents or concerns arise. Equally, Health Education England (HEE) must be assured that placements for doctors and dentists in training ('trainees') put appropriate protection and support mechanisms in place, covering both trainees and colleagues involved in the training process ('educators'). These measures are an essential part of facilitating a just and inclusive culture under an overarching banner of compassionate leadership, while at the same time ensuring that concerns, should they arise, are properly investigated.

The authors believe that an inclusive culture creates and maintains an inclusive workplace which allows all employees to achieve their fullest potential. A just culture helps NHS managers to ensure that all staff involved in a patient safety incident are treated fairly and supports a culture of openness to maximise opportunities to learn from mistakes. NHS Improvement's just culture guide supports conversations between managers regarding whether a staff member involved in an incident requires specific individual support or intervention to work safely. It also highlights that actions which single out an individual employee are rarely appropriate, as most patient safety issues have deeper causes and require wider action (NHS Improvement, 2018).

A prevailing culture of blame in healthcare has been suggested as a major source of an unacceptably high number of medical errors. Moving from a blame culture to a just culture requires a comprehensive understanding of the organisational attributes or antecedents that can con contribute to the associated attitudes. A blame culture is more likely to occur in healthcare organisations that rely predominantly on hierarchical, compliance-based functional management systems. Meanwhile, a just or learning culture is more likely to be present in organisations which elicit greater employee involvement in decision making. Healthcare organisations need to build on their organisational capacity, including their human resources (HR) management capabilities, to achieve a just culture (Khatri et al, 2009).

In June 2019 the General Medical Council published the final recommendations of its commissioned review - known as the Hamilton review - into how gross negligence manslaughter and culpable homicide are applied to medical practice (Hamilton, 2019). Despite their focus on incidents with the most serious outcomes, the recommendations of the Hamilton review are generally applicable to the investigation of concerns that can be raised within local organisations

Just two weeks before the release of these recommendations, Baroness Dido Harding, Chair of NHS Improvement, wrote to NHS Chief Executives and Chairs setting out the learning from the review of a tragic event in 2016, involving the death of a nurse formerly employed by an NHS organisation in London (Harding, 2019). Healthcare employers and managers will, if they are serious about fostering a just culture in their workplace, need to carefully consider and appropriately respond to the implications of both Baroness Harding's communication to NHS trusts and the Hamilton recommendations.

\section{Baroness Harding's letter and the NHS improvement advisory group}

In late 2015, a nurse (Mr Amin Abdullah) was the subject of an investigation and protracted disciplinary procedure which culminated in his summary dismissal from employment on the grounds of gross misconduct. In February 2016, just before his appeal hearing, Mr Abdullah tragically committed suicide. This tragic event resulted in the commissioning of an external review. The resulting report concluded that, in addition to serious procedural errors, throughout the investigation and disciplinary process Mr Abdullah was treated very poorly, causing severe detriment to his mental health (Verita, 2018). 
In response, NHS Improvement established a 'task and finish' advisory group to consider how widespread these failings were and what could be learned from them. The work of the advisory group resulted in a series of recommendations, some of which clearly require further discussion with stakeholders and some of which are suitable for immediate implementation. As a result, of NHS Improvement's work, Baroness Harding wrote to NHS trusts ask them to review their management and oversight of local investigation and disciplinary procedures. A series of questions were then posed (Figure 1). Healthcare employers should carefully consider the details of Baroness Harding's letter and provide assurance to all stakeholders that there is a just culture in their organisation, with investigations and disciplinary procedures being handled fairly, efficiently and compassionately.

Figure 1. Questions posed in Baroness Harding's letter to NHS Trust and NHS Foundation Trust Chief Executives and Chairs (Harding, 2019).

\section{How does the Trust Board oversee investigations and disciplinary procedures?}

2. In relation to any cases currently being considered and all future cases:

a. Is there sufficient understanding of the issues or concerns, and the circumstances relating to them, to justify the initiation of formal action?

b. Considering the circumstances, in the eyes of your organisation and others external to it, would the application of a formal procedure represent a proportionate and justifiable response (i.e. have other potential responses and remedies, short of formal intervention, been fully assessed before being discounted)?

c. If formal action is being or has been taken, how will appropriate resources be allocated and maintained to ensure it is conducted fairly and efficiently; how are you ensuring that independence and objectivity is maintained at every stage of the process?

d. What will be the likely impact on the health and wellbeing of the individual(s) concerned and on their respective teams and services, and what immediate and ongoing direct support will be provided to them? Further, how will you ensure the dignity of the individual(s) is respected at all times and in all communications, and that your duty of care is not compromised in any way, at any stage?

e. For any current case that is concluding, where it is possible that a sanction will be applied, are similar questions being considered?

At a local level, the authors believe that the response to Baroness Harding's letter should be in the form of an assurance document. NHS organisations should review their local procedures against the guidance accompanying the letter and provide:

- A response to the above questions in relation to current cases 
- Assurance of the processes that are in place within the organisation to address these questions in relation to future cases.

\section{The Hamilton review}

Separate to the NHS Improvement advisory group's work, the General Medical Council commissioned the Hamilton review following the tragic death of a six-year-old patient in Leicester. The senior paediatrician involved in the child's care was subsequently convicted of gross negligence manslaughter and given a 2-year custodial sentence (General Medical Council, 2019). This case also prompted the Secretary of State for Health and Social Care to announce a review of the application of gross negligence manslaughter in the NHS (Iacobucci, 2018).

The Hamilton review contains 29 recommendations (Appendix 1). A significant number of these recommendations are likely to warrant action from healthcare employers and educators even in advance of a national implementation plan from the General Medical Council, including recommendations 3 and 4 (families and healthcare staff), recommendations 5, 6, 8 and 9 (equality, diversity and inclusion), recommendation 10 (system scrutiny and assurance), recommendations 15 and 16 (local investigations into patient safety incidents), recommendation 18 (preparedness for Coroner and Procurator Fiscal proceedings), recommendation 26 (reflective practice) and recommendations 27 and 28 (support for doctors) (Hamilton, 2019).

This was not the first time that the methods used to address cases of gross negligence manslaughter and other potential misconduct in healthcare has been challenged. In November 2013, a consultant surgeon was found guilty of manslaughter by gross negligence and sentenced to over two years immediate custody (Judiciary of England and Wales, 2013). It was not until 2018 that the Medical Practitioners Tribunal Service found no charges against him had been proved (Dyer, 2018). It has been subsequently suggested that a criminal court is not the right place to determine blame in complex clinical cases (Vaughan, 2018) and that perhaps a more coherent and reproducible approach is required in cases with such serious potential consequences as gross negligence manslaughter (Wheeler, 2018).

Aside from individual doctors being investigated in relation to potential criminal matters, organisations have also faced investigations into serious patient safety concerns. In 2017 an independent review of maternity services (the Ockenden review) was conducted at Shrewsbury and Telford Hospital NHS Trust following a number of serious clinical incidents (NHS Improvement, 2019). The Ockenden Review was originally tasked in relation to 23 cases, but in January 2020 it was announced that, following identification of additional cases, the total number of cases relevant to the scope of the review now stands at 900, a small number of which go back 40 years (Dorries, 2020). The final outcome of that review is not yet known. However, there have already been calls to make responding to clinical error part of the core curriculum for medical and nursing students, and for clinical teams to be trained together in recognising risk and in responding appropriately to clinical problems (Kirkup, 2019).

\section{What do these recommendations mean for healthcare professionals, employers and educators?}

At the outset it has to be highlighted that the focus of the Hamilton review is on the GMC who commissioned the report. However, the principles set out in the review are vital for all healthcare employers to understand and action (Appendix 1). 
NHS Trusts will be well versed in dealing with the statutory duty of candour (The Health and Social Care Act 2008 (Regulated Activities) Regulations, 2014 \& Care Quality Commission, 2017). The statutory duty of candour is, in brief, a legal duty to be open and honest with patients and service users, or their families, when something goes wrong that appears that have caused, or could lead to, significant harm.

Individual healthcare employers and educators should review their organisation's processes to ensure that training regarding the professional duty of candour is provided both locally and within specialised training programmes. The professional duty of candour is that every healthcare professional must be open and honest with patients when something that goes wrong with their treatment or care causes, or has the potential to cause, harm or distress. This means that healthcare professionals must tell the patient (or, where appropriate, the patient's advocate, carer or family) when something has gone wrong, apologise to the patient (or, where appropriate, the patient's advocate, carer or family), offer an appropriate remedy or support to put matters right (if possible) and explain fully to the patient (or, where appropriate, the patient's advocate, carer or family) the short and long term effects of what has happened (Nursing and Midwifery Council and General Medical Council, 2019). Healthcare professionals must also be open and honest with their colleagues, employers and relevant organisations, and take part in reviews and investigations when requested. They must also be open and honest with their regulators, raising concerns where appropriate. They must support and encourage each other to be open and honest, and not stop someone from raising concerns (Nursing and Midwifery Council and General Medical Council, 2019).

NHS organisations must carefully consider the support structures they have in place for doctors involved in incidents to ensure that involvement of, and support for, families and staff during the investigation of those incidents is coordinated and well-led. Recommendation three of the Hamilton Review indicates that following an unexpected death, there should be close adherence to the professional and statutory duty of candour to be open and honest with the family of the deceased. They need to be told as fully as possible what has happened, why it happened and be assured that they will be kept involved and informed throughout the investigation (Hamilton, 2019). The authors believe that if a doctor in training is involved in an incident which triggers the professional duty of candour, there must be immediate access to a senior clinician to provide face-to-face support, guidance and advice about that duty, as well as to take the lead in liaison with the patient and/or family.

In effect, although the professional duty of candour is an individual duty required by an external regulator, there should never be a situation in which a healthcare professional below the level of consultant or fully trained GP is left or expected to carry out the requirements of that duty without face-to-face senior support.

There is also a key role to play by healthcare organisations regarding the support provided to practitioners who are new to UK practice. Prior to any national induction pacakage being made available to employers, they should ensure that their induction processes are comprehensive for all healthcare professionals who are new to UK practice, regardless of whether they are in training or fully qualified. Such an approach is entirely consistent with Recommendation 5 of the Hamilton Review which recommends that the General Medical Council should work with healthcare service providers, national bodies and representatives of overseas doctors to develop a suite of support for doctors new to UK practice (Hamilton, 2019). This should include information about cultural and social issues, the structure of the NHS, contracts and organisation of training, unduction, appraisal and revalidation, professional development plans and mentoring (Hamilton, 2019).

The Hamilton review recommends that, when a healthcare professional is investigated for gross negligence manslaughter or culpable homicide, the systems within their department should be 
scrutinised by an external authority. If the individual under investigation is a trainee, this should include scrutiny of the department's education and training environment. While this recommendation was made with gross negligence manslaughter or culpable homicide in mind, it also has general applicability to any investigation involving concerns raised about a healthcare professional. Indeed, the Department of Health's (2003) maintaining high professional standards initiative requires investigations to encompass an assessment of the extent to which system failures caused or contributed to the concerns raised about an individual. Concerns raised about healthcare professionals can include, for example, concerns about their personal conduct, concerns about professional conduct, concerns about their health, concerns about capability and professional performance or concerns about whether they have been convicted of a criminal offence, which might affect their suitability to continue in their role as a regulated healthcare professional. NHS England has published a useful guide for responding to concerns raised about medical practice (Conlon \& Kirk, 2019).

Healthcare employers and educators need clear guidance regarding the local implementation of the Hamilton review recommendations that are most applicable to their work involved in either employing or training doctors. However, to the authors' knowledge, such guidance has not yet been made available. Table 1 sets out the actions which, having considered both the Hamilton review and Baroness Harding's letter to NHS trusts, the authors believe healthcare employers and educators can take immediately, without waiting for an implementation plan from the General Medical Council (GMC) covering all four nations of the United Kingdom. The GMC's initial response to the Hamilton Review 2019 indicates that work is underway to address some of the issues that were raised by Hamilton, but it is not clear when futher announcements will be made about new strategies to address all of the issues raised (General Medical Council, 2019b).

The recommendations set out in this table are specific to the English NHS and are presented to stimulate discussion and local action without delay. Separate arrangements will be needed for general practices, given the different governance arrangements in place compared with NHS trusts. Similarly, alternative recommendations will be needed for Wales, Northern Ireland and Scotland, where the structure of NHS organisations differs from those in England. 
Table 1. Ensuring support during local investigations

\begin{tabular}{|c|c|c|}
\hline & $\begin{array}{l}\text { Responsible } \\
\text { body or office- } \\
\text { holder }\end{array}$ & Local recommendation \\
\hline $\mathbf{A}$ & $\begin{array}{l}\text { Health } \\
\text { Education } \\
\text { England } \\
\text { postgraduate } \\
\text { deans }\end{array}$ & $\begin{array}{l}\text { Postgraduate deans within each Health Education } \\
\text { England area should ensure that each speciality } \\
\text { training programme available in that area contains } \\
\text { sufficient training regarding the professional duty } \\
\text { of candour at an early stage in the programme }\end{array}$ \\
\hline B & $\begin{array}{l}\text { Medical } \\
\text { directors of } \\
\text { NHS trusts }\end{array}$ & $\begin{array}{l}\text { NHS trusts should ensure that within their } \\
\text { organisation: } \\
\text { - local mandatory training programmes } \\
\text { contain sufficient training regarding the } \\
\text { professional duty of candour at an early } \\
\text { stage in the programme } \\
\text { - where a doctor in training is involved in an } \\
\text { incident in which the professional duty of } \\
\text { candour is triggered, there is immediate } \\
\text { access to a senior clinician to provide face- } \\
\text { to-face support, guidance and advice about } \\
\text { that duty, as well as to take the lead in } \\
\text { liaison with the patient and/or family }\end{array}$ \\
\hline $\mathbf{C}$ & $\begin{array}{l}\text { Medical } \\
\text { directors and } \\
\text { directors of } \\
\text { nursing in NHS } \\
\text { trusts }\end{array}$ & $\begin{array}{l}\text { The boards of NHS trusts and the postgraduate } \\
\text { dean(s) in each Health Education England region } \\
\text { should receive assurance that clear policies are in } \\
\text { place to ensure consistent implementation of the } \\
\text { relevant national frameworks in relation to } \\
\text { involvement of, and support for, families and staff } \\
\text { following an unexpected death }\end{array}$ \\
\hline $\mathbf{D}$ & $\begin{array}{l}\text { Medical } \\
\text { directors and } \\
\text { directors of } \\
\text { people of NHS } \\
\text { trusts; and } \\
\text { Health } \\
\text { Education } \\
\text { England } \\
\text { postgraduate } \\
\text { deans }\end{array}$ & $\begin{array}{l}\text { NHS Trusts should work with Health Education } \\
\text { England to ensure that they have a comprehensive } \\
\text { induction package for doctors new to UK practice } \\
\text { (whether trainee or non-trainee). This should } \\
\text { include information about cultural and social } \\
\text { issues, the structures of the NHS, contracts, and } \\
\text { the organisation of training, inductions, appraisals, } \\
\text { revalidation, professional development plans and } \\
\text { mentoring. When a national induction package is } \\
\text { made available, this should be adopted, with local } \\
\text { adaptation where necessary }\end{array}$ \\
\hline $\mathbf{E}$ & $\begin{array}{l}\text { Directors of } \\
\text { people of NHS } \\
\text { trusts }\end{array}$ & $\begin{array}{l}\text { An assurance paper should be presented to each } \\
\text { NHS trust board setting out the available evidence } \\
\text { that employees and leaders understand the } \\
\text { importance of an inclusive culture within the } \\
\text { workplace and training environments. This paper } \\
\text { should be reviewed annually }\end{array}$ \\
\hline $\mathbf{F}$ & $\begin{array}{l}\text { Directors of } \\
\text { people and } \\
\text { medical }\end{array}$ & $\begin{array}{l}\text { During education and inspection visits, Health } \\
\text { Education England should require assurance of } \\
\text { and evidence that an inclusive culture within the }\end{array}$ \\
\hline
\end{tabular}




\begin{tabular}{|c|c|c|}
\hline & $\begin{array}{l}\text { directors of } \\
\text { NHS trusts }\end{array}$ & $\begin{array}{l}\text { workplace (including the education and training } \\
\text { environments) is understood and in place }\end{array}$ \\
\hline $\mathbf{G}$ & $\begin{array}{l}\text { Directors of } \\
\text { people of NHS } \\
\text { trusts }\end{array}$ & $\begin{array}{l}\text { NHS trusts should have published measures, } \\
\text { reported annual and aspirations for diverse } \\
\text { workforce representation in key roles and at all } \\
\text { levels of decision making. These published } \\
\text { measures and aspirations should be made } \\
\text { available to all managers and employers working } \\
\text { within the organisation, as well as to the relevant } \\
\text { Health Education England postgraduate dean(s) }\end{array}$ \\
\hline $\mathbf{H}$ & $\begin{array}{l}\text { Directors of } \\
\text { people and } \\
\text { medical } \\
\text { directors of } \\
\text { NHS trusts }\end{array}$ & $\begin{array}{l}\text { The boards of NHS trusts and the relevant Health } \\
\text { Education England postgraduate dean(s) should } \\
\text { receive assurance of the processes in place within } \\
\text { the NHS organisation to ensure: } \\
\text { - Fair decision making } \\
\text { - Equality, diversity and inclusion training } \\
\text { - Unconscious bias training } \\
\text { - Auditing } \\
\text { - Monitoring of the above processes and } \\
\text { outcomes }\end{array}$ \\
\hline I & $\begin{array}{l}\text { Medical } \\
\text { directors of } \\
\text { NHS trusts and } \\
\text { responsible } \\
\text { officers (NHS } \\
\text { England, n.d.) }\end{array}$ & $\begin{array}{l}\text { When concerns are raised about an individual and } \\
\text { an investigation is proposed under the maintaining } \\
\text { high professional standards in the modern NHS } \\
\text { framework, response procedures must ensure that } \\
\text { the following are scrutinised: } \\
\text { - the systems within the departments where } \\
\text { the individual works, or worked } \\
\text { - the education and training environment }\end{array}$ \\
\hline $\mathbf{J}$ & $\begin{array}{l}\text { Medical } \\
\text { directors and } \\
\text { directors of } \\
\text { people of NHS } \\
\text { trusts }\end{array}$ & $\begin{array}{l}\text { Boards of NHS trusts should be assured that: } \\
\text { - there is a sufficient number of experienced } \\
\text { case investigators within the organisation } \\
\text { with the time, appropriate experience, } \\
\text { skills and competence (including } \\
\text { understanding of human factors) to } \\
\text { undertake investigation } \\
\text { - local support mechanisms are in place to } \\
\text { provide support to staff involved in } \\
\text { investigations } \\
\text { The assurance report should be made publicly } \\
\text { available and shared with any external } \\
\text { employer(s) working within the trust and with the } \\
\text { relevant Health Education England postgraduate } \\
\text { dean }\end{array}$ \\
\hline
\end{tabular}




\begin{tabular}{|c|c|c|}
\hline $\mathbf{K}$ & $\begin{array}{l}\text { Directors of } \\
\text { people and } \\
\text { medical } \\
\text { directors of } \\
\text { NHS trusts }\end{array}$ & $\begin{array}{l}\text { The boards of NHS trusts should be assured that a } \\
\text { robust quality assurance process exists to review } \\
\text { the effective application of local investigation } \\
\text { frameworks, including a specific focus on how } \\
\text { human factors are addressed within investigation } \\
\text { processes. The assurance report should be made } \\
\text { publicly available and shared with any external } \\
\text { employer(s) working within the trust and with the } \\
\text { relevant Health Education England postgraduate } \\
\text { dean(s) }\end{array}$ \\
\hline $\mathbf{L}$ & $\begin{array}{l}\text { Directors of } \\
\text { people and } \\
\text { medical } \\
\text { directors of } \\
\text { NHS trusts }\end{array}$ & $\begin{array}{l}\text { Each healthcare organisation should set out the } \\
\text { support and guidance available for staff who are } \\
\text { involved in a dignity at work, grievance, } \\
\text { maintaining high professional standards or patient- } \\
\text { safety (clinical governance) investigation in a } \\
\text { comprehensive document }\end{array}$ \\
\hline $\mathbf{M}$ & $\begin{array}{l}\text { Health } \\
\text { Education } \\
\text { England } \\
\text { postgraduate } \\
\text { deans }\end{array}$ & $\begin{array}{l}\text { Health Education England postgraduate deans } \\
\text { should review and, where necessary, update the } \\
\text { guidance given to trainees regarding the support } \\
\text { available to those in difficulty or requiring extra } \\
\text { support during their training programme, } \\
\text { including those returning to work following a } \\
\text { prolonged absence }\end{array}$ \\
\hline $\mathbf{N}$ & $\begin{array}{l}\text { Responsible } \\
\text { officers and } \\
\text { medical } \\
\text { directors of } \\
\text { NHS trusts }\end{array}$ & $\begin{array}{l}\text { Healthcare professionals reflecting on significant } \\
\text { events should use the reflective practitioner } \\
\text { guidance (The Academy of Medical Royal } \\
\text { Colleges, the Conference of UK Postgraduate } \\
\text { Medical Deans, the General Medical Council and } \\
\text { the Medical Schools Council, 2019) and toolkit. In } \\
\text { any correspondence with employees about } \\
\text { significant events, reference to this guidance and } \\
\text { toolkit should be made }\end{array}$ \\
\hline $\mathbf{O}$ & $\begin{array}{l}\text { Health } \\
\text { Education } \\
\text { England } \\
\text { postgraduate } \\
\text { deans }\end{array}$ & $\begin{array}{l}\text { Health Education England postgraduate deans } \\
\text { should ensure that information is provided to } \\
\text { everyone joining a training post or programme } \\
\text { concerning the limits of NHS basic indemnity and } \\
\text { the support available to those who are involved in } \\
\text { a future investigation or who are in difficulty. A } \\
\text { factsheet should also be published summarising } \\
\text { these issues }\end{array}$ \\
\hline $\mathbf{P}$ & $\begin{array}{l}\text { Medical } \\
\text { directors of } \\
\text { NHS trusts }\end{array}$ & $\begin{array}{l}\text { Medical directors of NHS trusts should ensure that } \\
\text { the induction for staff working at their } \\
\text { organisation includes information on the limits of } \\
\text { NHS basic indemnity and the support available to } \\
\text { individuals who are undergoing a future } \\
\text { investigation or who are in difficulty. A factsheet } \\
\text { should also be published, summarising these } \\
\text { issues }\end{array}$ \\
\hline $\mathbf{Q}$ & $\begin{array}{l}\text { Health } \\
\text { Education } \\
\text { England }\end{array}$ & $\begin{array}{l}\text { Health Education England postgraduate deans } \\
\text { should provide guidance to healthcare } \\
\text { professionals regarding what constitutes a } \\
\text { 'significant absence' of a trainee }\end{array}$ \\
\hline
\end{tabular}




\begin{tabular}{|l|l|l|}
\hline & $\begin{array}{l}\text { postgraduate } \\
\text { deans }\end{array}$ & $\begin{array}{l}\text { Directors of } \\
\text { people and } \\
\text { medical } \\
\text { directors of } \\
\text { NHS trusts }\end{array}$ \\
\hline $\mathbf{R}$ & $\begin{array}{l}\text { NHS trusts, in conjunction with Health Education } \\
\text { England, should provide guidance to healthcare } \\
\text { professionals regarding what constitutes a } \\
\text { 'significant absence' and the relevant NHS trust } \\
\text { board(s) and Health Education England } \\
\text { postgraduate dean should receive assurance that } \\
\text { there is a robust process of return to work } \\
\text { arrangements for staff following a significant } \\
\text { absence, including re-integration into the } \\
\text { workplace and training }\end{array}$ \\
\hline
\end{tabular}




\section{CONCLUSIONS}

Healthcare employers and educators have a responsibility to consider how they will implement each of the above recommendations in relation to both Baroness Harding's letter to NHS Trust Chairs and Chief Executives and the local recommendations which stem directly from Hamilton review (Appendix 2). The investigation of smaller incidents, and the appropriate, sensitive publication of their findings with lessons to be learned that may be applicable across the NHS, may be a means of preventing larger, or more serious, incidents going forwards.

In order to prevent issues from being considered in isolation and common trends from being missed, investigation reports and action plans should be reviewed on a regular basis. Such investigations must not be conducted to hold any individual to account as there are other processes for that purpose, including the various regulatory bodies in the UK.

Ensuring that healthcare professionals are appropriately supported when incidents occur and that the investigation of those incidents is thorough and appropriate can only occur when there is a just culture facilitated by compassionate leadership within an organisation.

\section{Conflicts of interest}

The authors have no conflicts of interest to declare. 


\section{REFERENCES}

Academy of Medical Royal Colleges, the Conference of UK Postgraduate Medical Deans, the General Medical Council and the Medical Schools Council. The reflective practitioner: guidance for doctors and medical students. n.d.

https://www.gmc-uk.org/education/standards-guidance-and-curricula/guidance/reflectivepractice/the-reflective-practitioner-guidance-for-doctors-and-medical-students (accessed 20 June 2019)

Department of Health. Maintaining High Professional Standards in the Modern NHS (MHPS). London: Department of Health of Her Majesty's Government; 2003.

https://webarchive.nationalarchives.gov.uk/20130124065523/http:/www.dh.gov.uk/prod_consum_dh /groups/dh_digitalassets/@dh/@en/documents/digitalasset/dh_4103344.pdf (accessed 20 June 2019)

Care Quality Commission. Regulation 20: Duty of Candour. London: Care Quality Commission; 2017.

https://www.cqc.org.uk/guidance-providers/regulations-enforcement/regulation-20-dutycandour\#guidance (accessed 14 March 2020)

Conlon M \& Kirk J. A practical guide for responding to concerns about medical practice. Leeds, UK: NHS England; 2019

https://www.england.nhs.uk/wp-content/uploads/2019/03/practical-guide-for-responding-toconcerns-about-medical-practice-v1.pdf (accessed 14 March 2020)

Dorries N. Ockenden Review of Maternity Care: Shrewsbury and Telford. Hansard. London: UK Parliament. 2020.

https://hansard.parliament.uk/Commons/2020-01-15/debates/36439E95-F236-4742-B379-

9CB10389D712/OckendenReviewOfMaternityCareShrewsburyAndTelford (accessed 14 March 2020)

Dyer C. Sellu is cleared of medical misconduct. BMJ 2018;360:k1089.

https://www.bmj.com/content/360/bmj.k1089

General Medical Council. Dr Hadiza Bawa-Garba. 2019a.

https://www.bmj.com/bawa-garba (accessed 14 March 2020)

General Medical Council. GMC statement following the publication of the independent review of gross negligence manslaughter and culpable homicide in medical practice. London: General Medical Council; 6 June 2019b

https://www.gmc-uk.org/news/news-archive/gnm-statement (accessed 14 March 2020)

Hamilton L. Independent review of gross negligence manslaughter and culpable homicide. London: General Medical Council; 2019.

https://www.gmc-uk.org/about/how-we-work/corporate-strategy-plans-and-impact/supporting-aprofession-under-pressure/independent-review-of-medical-manslaughter-and-culpable-homicide (accessed 20 June 2019)

Harding D. Learning lessons to improve our people practices. London: NHS Improvement; 2019. https://i.emlfiles4.com/cmpdoc/9/7/2/8/1/1/files/56794_letter-to-chairs-and-chief-executives-24may-

2019.pdf?utm_campaign $=2381883$ _Letter $\% 20$ from $\% 20$ Dido $\% 2023 \% 20 \mathrm{May} \% 202019 \& u$ tm_mediu $\mathrm{m}=$ email\&utm_source=Monitor\&utm_orgtype $=$ NHS $\% 20$ Trust\&dm_i=2J9J,1F1VF,4ARAKA $\overline{-}, 4$ PG6 R,1 (accessed 20 June 2019) 
Iacobucci G. Health secretary orders review into use of medical manslaughter. BMJ. 2018;360:592. Judiciary of England and Wales. Setencing remarks of Mr Justice Nicol. 2013.

https://www.judiciary.gov.uk/ wp-content/uploads/JCO/Documents/Judgments/r-v- sellu-sentencingremarks.pdf

Khatri N, Brown GD, Hicks LL. From a blame culture to a just culture in health care. Health Care Mangement Review. 2009;34(4): 312-322.

Kirkup B. The NHS has failed to learn the lessons of Morecambre Bay - with devastating consequences. The Independent. 19 November 2019.

https://www.independent.co.uk/voices/nhs-maternity-scandal-hospitals-report-changes-actiona9207221.html

NHS England. Responsible Officers. N.d. https://www.england.nhs.uk/medical-revalidation/ro/ NHS Improvement. A just culture guide. London: NHS Improvement; 2018. https://improvement.nhs.uk/resources/just-culture-guide/ (accessed 20 June 2019)

NHS Improvement. Terms of Reference for Independent Review of Maternity Services at Shrewsbury and Telford Hospital NHS Trust. 2019.

https://improvement.nhs.uk/documents/6192/ToR-SaTH-Maternity-Independent-Review-RevisedNovember-2019.pdf

Nursing and Midwifery Council and General Medical Council. Openness and honesty when things go wrong: the professional duty of candour. London, UK: Nursing and Midwifery Council and General Medical Council; 2019

https://www.gmc-uk.org/-/media/documents/openness-and-honesty-when-things-go-wrong--theprofessional-duty-of-cand pdf-

61540594.pdf?la=en\&hash=EEB52EBEDBFA0EA421F4736F4C36BAB730A9E567 (accessed 14 March 2020)

The Health and Social Care Act 2008 (Regulated Activities) Regulations 2014. Regulation 20: Duty of Candour. London: UK Parliament; 2014

https://www.legislation.gov.uk/ukdsi/2014/9780111117613/regulation/20 (accessed 14 March 2020)

Vaughan J. The case of David Sellu: a criminal court is not the right place to determine blame in complex criminal cases. BMJ online. 20 March 2018.

https://blogs.bmj.com/bmj/2018/03/20/the-case-of-david-sellu-a-criminal-court-is-not-the-rightplace-to-determine-blame-in-complex-clinical-cases/

Verita. Independent investigation into the management of the trust's disciplinary process resulting in the dismissal of Mr Amin Abdullah. London: Imperial College Healthcare NHS Trust; 2018. https://www.verita.net/wp-content/uploads/2018/08/Imperial-Final-report-9-August-18.pdf (accessed 20 June 2019)

Wheeler R. Gross Ngligence manslaughter: what does 'gross' entail? Clinical Law Updates. Southampton: University Hospital Southamptom NHS Foundation Trust. 2018. https://www.uhs.nhs.uk/HealthProfessionals/Clinical-law-updates/Clinicallawupdates.aspx 
Appendix 1. Selected recommendations within the Hamilton review (Hamilton, 2019) which the authors of this paper in the British Journal of Healthcare Management consider are most applicable to employers of doctors and/or Health Education England

\begin{tabular}{|c|c|}
\hline Topic & Hamilton review recommendation \\
\hline \multirow[t]{2}{*}{$\begin{array}{l}\text { Families and } \\
\text { healthcare staff }\end{array}$} & $\begin{array}{l}\text { (3) Following an unexpected death, there should be close } \\
\text { adherence to the professional and statutory duty of candour to be } \\
\text { open and honest with the family of the deceased. They need to be } \\
\text { told as fully as possible what has happened, why it happened and } \\
\text { be assured that they will be kept involved and informed } \\
\text { throughout the investigation }\end{array}$ \\
\hline & $\begin{array}{l}\text { (4) Involvement of, and support, for families and staff is often } \\
\text { deficient in the period between an unexpected death and the start } \\
\text { of a patient safety investigation. All healthcare service providers } \\
\text { should have clear policies and a named lead to ensure consistent } \\
\text { implementation of policies in line with the relevant national } \\
\text { frameworks }\end{array}$ \\
\hline \multirow[t]{4}{*}{$\begin{array}{l}\text { Equality, diversity } \\
\text { and inclusion }\end{array}$} & $\begin{array}{l}\text { (5) The GMC should work with healthcare service providers, } \\
\text { national bodies and representatives of overseas doctors to } \\
\text { develop a suite of support for doctors new to UK practice. This } \\
\text { should include information about cultural and social issues, the } \\
\text { structures of the NHS, contracts and organisation of training, } \\
\text { induction, appraisal and revalidation, professional development } \\
\text { plans and mentoring }\end{array}$ \\
\hline & $\begin{array}{l}\text { (6) The GMC should work with stakeholders across the } \\
\text { healthcare systems to ensure that the importance of an inclusive } \\
\text { culture within the workplace, education and training } \\
\text { environments is understood }\end{array}$ \\
\hline & $\begin{array}{l}\text { (8) To ensure confidence in fair decision making, relevant } \\
\text { healthcare sector organisations (including the GMC) should have } \\
\text { published measures and aspirations for diverse workforce } \\
\text { representation in key roles and at all levels involved in decision } \\
\text { making }\end{array}$ \\
\hline & $\begin{array}{l}\text { (9) Relevant healthcare sector organisations (including the GMC) } \\
\text { should have in place appropriate methods of assurance of fair } \\
\text { decision making, including (but not limited to) equality, diversity } \\
\text { and inclusion training, unconscious bias training, auditing and } \\
\text { monitoring }\end{array}$ \\
\hline $\begin{array}{l}\text { System scrutiny } \\
\text { and assurance }\end{array}$ & $\begin{array}{l}\text { (10) Where a doctor is being investigated for gross negligence } \\
\text { manslaughter or culpable homicide, the appropriate external } \\
\text { authority should scrutinise the systems within the department } \\
\text { where the doctor worked. Where the doctor is a trainee, this } \\
\text { should include scrutiny of the education and training } \\
\text { environment by bodies responsible for education and training }\end{array}$ \\
\hline $\begin{array}{l}\text { Local } \\
\text { investigations into } \\
\text { patient safety } \\
\text { incidents }\end{array}$ & $\begin{array}{l}\text { (15) Improvements in patient safety are most likely to come } \\
\text { through local investigations into patient safety incidents which } \\
\text { are focused on learning not blame. We strongly endorse recent } \\
\text { developments in the frameworks for investigations. These } \\
\text { emphasise the need for the investigation team to have the time } \\
\text { and the appropriate experience, skills and competence (including } \\
\text { understanding of human factors) to undertake investigations, and } \\
\text { the necessary degree of externality to command confidence in the }\end{array}$ \\
\hline
\end{tabular}




\begin{tabular}{|c|c|}
\hline & $\begin{array}{l}\text { process. We also stress the need to involve and support families } \\
\text { and staff }\end{array}$ \\
\hline & $\begin{array}{l}\text { (16) The appropriate authorities in the four UK countries should } \\
\text { quality assure the effective application of local investigation } \\
\text { frameworks for patient safety incidents. This external scrutiny } \\
\text { should include a specific focus on how healthcare service } \\
\text { providers address human factors issues within their investigation } \\
\text { processes }\end{array}$ \\
\hline $\begin{array}{l}\text { Preparedness for } \\
\text { Coroner and } \\
\text { Procurator Fiscal } \\
\text { proceedings }\end{array}$ & $\begin{array}{l}\text { (18) Healthcare service providers should provide support and } \\
\text { guidance for doctors who are involved in an inquest or fatal } \\
\text { accident inquiry so that they have an appropriate understanding } \\
\text { of the process and their role in proceedings }\end{array}$ \\
\hline Reflective practice & $\begin{array}{l}\text { (26) Doctors' reflective practice is fundamental to their } \\
\text { professionalism. We recommend that doctors use the Reflective } \\
\text { Practitioner guidance and supporting toolkit to help them engage } \\
\text { in reflective practice. This will support doctors' learning while } \\
\text { limiting the possible relevance of any recorded reflections in } \\
\text { other proceedings. UK Parliament and the devolved governments } \\
\text { should consider how these reflections could be given legal } \\
\text { protection }\end{array}$ \\
\hline \multirow[t]{2}{*}{$\begin{array}{l}\text { Support for } \\
\text { doctors }\end{array}$} & $\begin{array}{l}\text { (27) The GMC should work with the medical trade unions, } \\
\text { medical defence organisations, healthcare service providers, } \\
\text { education and training bodies and other professional bodies to } \\
\text { explore how doctors under investigation might be better } \\
\text { supported. Doctors should be made aware that NHS basic } \\
\text { indemnity for clinical negligence claims does not cover legal } \\
\text { advice and support for any other processes (GMC, coroner or } \\
\text { criminal) }\end{array}$ \\
\hline & $\begin{array}{l}\text { (28) Healthcare service providers should provide induction and } \\
\text { support for all doctors returning to clinical practice after a period } \\
\text { of significant absence. These doctors should have a return to } \\
\text { work meeting and appropriate supervision and support during the } \\
\text { induction period tailored to the needs of the individual }\end{array}$ \\
\hline
\end{tabular}



organisations

Key actions for Health Education England (HEE)

1. Postgraduate Deans within each HEE area should ensure that each speciality training programme available in that area contains sufficient training regarding the professional duty of candour at an early stage in the programme

2. HEE should require, during education and inspection visits, assurance of, and evidence that, an inclusive culture within the workplace (including education and training environments) is understood and is in place

3. Where concerns are raised about a doctor, and an investigation is proposed under the Maintaining High Professional Standards in the Modern NHS (MHPS) framework, the terms of reference should ensure that scrutiny takes place of:

- the systems within the departments where the doctor works, or worked; and

- for doctors in training, the education and training environment

4. HEE Postgraduate Deans should review, and where necessary update, the guidance given to doctors and dentists in training regarding the support available to those in difficulty or trainees requiring extra support during their training programme, including those returning to work following a prolonged absence

5. Doctors reflecting on significant events should use the Reflective Practitioner guidance (The Academy of Medical Royal Colleges, the Conference of UK Postgraduate Medical Deans, the General Medical Council and the Medical Schools Council, 2019) and toolkit. In any correspondence with doctors about significant events, reference to this guidance and toolkit should be made

6. HEE Postgraduate Deans should ensure information is provided to everyone 


\begin{tabular}{|l|}
\hline joining a training post or programme, \\
concerning the limits of NHS basic \\
indemnity, and the support available to \\
those who are involved in a future \\
investigation or who are in difficulty. A \\
factsheet should be published by HEE, \\
summarising the issues \\
\hline 7. \\
The Postgraduate Dean(s) in each HEE \\
region should receive assurance that clear \\
policies are in place in each NHS \\
organisation in that region hosting doctors \\
and dentists in training to ensure consistent \\
implementation of the relevant national \\
frameworks in relation to involvement of, \\
and support for, families and staff \\
following an unexpected death
\end{tabular}

Key actions for NHS Trusts (via the Board of Directors)

9. NHS Trusts employing or hosting (ie providing a placement for) doctors should ensure that within their organisation:

- local mandatory training programmes contain sufficient training regarding the professional duty of candour at an early stage in the programme; and

- where a doctor in training is involved in an incident in which the professional duty of candour is triggered, there is immediate access to a senior clinician to provide faceto-face support, guidance and advice about that duty, as well as to take the lead in liaison with the patient and/or family

10. The Boards of NHS Trusts as well as the Postgraduate Dean(s) in each HEE region should receive assurance that clear policies are in place to ensure consistent implementation of the relevant national frameworks in relation to involvement of, and support for, families and staff following an unexpected death

11. NHS Trusts employing doctors should work with HEE to ensure that they have a 
comprehensive induction package for doctors new to UK practise (whether trainee or non-trainee) including information about cultural and social issues, the structures of the NHS, contracts and organisation of training, induction, appraisal and revalidation, professional development plans and mentoring. When a national induction package is made available this should be adopted, with local adaptation where necessary

12. An assurance paper should be presented to each NHS Trust Board setting out the available evidence that the importance of an inclusive culture within the workplace and education and training environments is understood; and this paper should be annually reviewed

13. Each NHS Trust should provide HEE with assurance that an inclusive culture within the workplace (including education and training environments) is understood and is in place

14. NHS Trusts should have published measures, reported annual, and aspirations for diverse workforce representation in key roles and at all levels involved in decision making. These published measures and aspirations should be made available to the employers of any doctors working at that organisation, as well as to the relevant HEE Postgraduate Dean(s)

15. The Boards of NHS Trusts and the relevant HEE Postgraduate Dean(s) should receive assurance of the processes in place within the NHS organisation to ensure:

- Fair decision making

- Equality, diversity and inclusion training

- Unconscious bias training

- Auditing; and

- Monitoring of the above processes and outcomes

16. Where concerns are raised about a doctor, and an investigation is proposed under the Maintaining High Professional Standards in the Modern NHS (MHPS) framework, 


\begin{tabular}{|l|}
\hline the terms of reference should ensure that \\
scrutiny takes place of: \\
the systems within the departments where \\
the doctor works, or worked; and \\
for doctors in training, the education and \\
training environment \\
\hline 17. Boards of NHS Trusts should be assured \\
that: \\
within the organisation there are sufficient \\
numbers of experienced case investigators \\
with the time and the appropriate \\
experience, skills and competence \\
(including understanding of human \\
factors) to undertake investigations; and \\
local support mechanisms are in place to \\
provide support to staff involved in \\
investigations \\
The assurance report should be made publicly \\
correspondence with doctors about \\
guidance (The Academy of Medical Royal \\
Colleges, the Conference of UK \\
Postgraduate Medical Deans, the General \\
Medical Council and the Medical Schools \\
available and shared with any external \\
employer(s) of doctors working within the Trust \\
and with the relevant HEE Postgraduate Dean
\end{tabular}




\begin{tabular}{|l|}
\hline $\begin{array}{l}\text { significant events, reference to this } \\
\text { guidance and toolkit should be made }\end{array}$ \\
\hline \begin{tabular}{l} 
21. Medical Directors of NHS Trusts should \\
ensure that the induction for doctors \\
working at their organisation includes \\
information on the limits of NHS basic \\
indemnity, and the support available to \\
doctors who are undergoing a future \\
investigation or who are in difficulty. A \\
factsheet should be published, \\
summarising the issues \\
\hline 22. NHS Trusts, in conjunction with HEE, \\
should provide guidance to doctors on \\
what constitutes a 'significant absence' \\
and the relevant NHS Trust Board(s) and \\
HEE Postgraduate Dean should receive \\
assurance that there is a robust process of \\
return to work arrangements for doctors \\
following a significant absence, \\
determined with support from NHS \\
Resolution and HEE where necessary, \\
including re-integration into the workplace \\
and education and training
\end{tabular} \\
\hline
\end{tabular}

